\title{
Can robotic liver resection compensate for weaknesses of the laparoscopic approach?
}

\author{
Daisuke Ban, Yoshiya Ishikawa, Minoru Tanabe \\ Department of Hepatobiliary and Pancreatic Surgery, Graduate School of Medicine, Tokyo Medical and Dental University, Tokyo, Japan \\ Correspondence to: Daisuke Ban, MD, PhD. Department of Hepatobiliary and Pancreatic Surgery, Graduate School of Medicine, Tokyo Medical and \\ Dental University; 1-5-45 Yushima, Bunkyo-ku, Tokyo 113-8519, Japan. Email: d-ban.msrg@tmd.ac.jp. \\ Provenance and Peer Review: This article was commissioned by the editorial office, Hepatobiliary Surgery and Nutrition. The article did not undergo \\ external peer review. \\ Comment on: Melstrom LG, Warner SG, Woo Y, et al. Selecting incision-dominant cases for robotic liver resection: towards outpatient hepatectomy \\ with rapid recovery. Hepatobiliary Surg Nutr 2018;7:77-84.
}

Submitted 17 Oct, 2019. Accepted for publication 31 Oct, 2019.

doi: 10.21037/hbsn.2019.11.02

View this article at: http://dx.doi.org/10.21037/hbsn.2019.11.02

In the past decade, the induction of minimal invasive surgery (MIS) has revolutionized liver surgery, because this approach greatly improves the clinical course of postoperative patients (1). At its inception, laparoscopic liver resection (LLR) was limited to minor resection, but improvements in the technique mean that the majority of the liver is now amenable to resection. Whereas minor resections are now performed worldwide, major and complicated resections remain concentrated in a limited number of expert centers. A recent study from four specialized hospitals showed an average annual percentage change of $12.5 \%$ vs. $-4.1 \%$ over a 15 -year period for laparoscopic and open procedures, respectively. Indeed, the curative rates of laparoscopy for diseases such as hepatocellular carcinoma and metastatic liver cancer are comparable to those of open surgery, and the incidence of surgical complications are lower (2). It can therefore be concluded that LLR is now an established first-line choice for optimal liver resection.

Robotic surgery has been widely adopted as an effective means of MIS to replace laparoscopic surgery in other fields such as gastric surgery, colorectal surgery, and urology. The introduction of robotics has introduced a higher degree of precision and has dramatically reduced the incidence of issues associated with tremor. Despite these clear advantages, liver resection centers have been slow to integrate the robotic approach, which is reminiscent of the delayed adoption of laparoscopic surgery by the liver resection field. In recent years, however, the number of papers on robotic liver resection (RLR) has increased rapidly.

Many retrospective studies have demonstrated the superiority of RLR compared to open liver resection (OLR) (3). For example, a meta-analysis study reported that RLR was associated with lower overall morbidity rates and a shorter hospital stay, whereas OLR was associated with shorter operative time (3). There were no differences between the two groups with regard to blood loss, blood transfusion requirements, $\mathrm{R} 0$ resection and mortality rates. The cumulative conversion rate was $4.6 \%$ in the RLR group. In addition, a shortened hospital stay is associated with reduced total costs, which may counterbalance the increased costs due to use of robotic devices. RLR may also be more cost-effective than conventional OLR, owing to lower total hospital direct costs such as ICU admissions and inpatient nursing and pharmacy costs (4). However, RLR is significantly more costly than LLR. A recently published meta-analysis demonstrated that RLR was associated with longer operative times, more blood loss and higher total cost (5). Of note, the authors pointed out that the increased blood loss in RLR has caused by limited energy devices that can be used and could also be attributed to the procedure being performed by less experienced surgeons. The prolonged operative time was attributed to lack of experience, a high percentage of major hepatectomies, and the length of time the robot was docked and undocked (5).

Theoretically, laparoscopic approach to the posterosuperior segment is difficult due to the rigidity of the straight laparoscopic instruments; these ergonomic restrictions prevent surgeons from performing the optimal 
Table 1 Laparoscopic liver resection of posterosuperior segment

\begin{tabular}{|c|c|c|c|c|c|c|c|}
\hline Author/year & $\mathrm{n}$ & $\begin{array}{l}\text { Operation time } \\
\qquad(\min )\end{array}$ & $\begin{array}{c}\text { Conversion } \\
(\%)\end{array}$ & $\begin{array}{c}\text { Positive margin } \\
\text { (\%) }\end{array}$ & $\begin{array}{l}\text { Blood loss } \\
\quad(\mathrm{mL})\end{array}$ & $\begin{array}{l}\text { Length of stay } \\
\text { (days) }\end{array}$ & $\begin{array}{c}\text { Mortality } \\
(\%)\end{array}$ \\
\hline Montalti et al. (11)/2016 & 72 & 295 [75-590] & 9.7 & 12.5 & $437[0-2,200]$ & $4.9[2-20]$ & 0 \\
\hline Scuderi et al. (13)/2017 & 86 & $215[52-540]$ & 3 & 10 & $200[0-2,000]$ & $4[1-11]$ & 0 \\
\hline D'Hondt et al. (14)/2018 & 35 & 140 [70-260] & 2.8 & 2.8 & $150[50-1,500]$ & 6 [3-39] & 0 \\
\hline
\end{tabular}

Table 2 Robotic liver resection of posterosuperior segment

\begin{tabular}{|c|c|c|c|c|c|c|c|}
\hline Author/year & $\mathrm{n}$ & $\begin{array}{l}\text { Operation time } \\
\qquad(\min )\end{array}$ & $\begin{array}{c}\text { Conversion } \\
(\%)\end{array}$ & $\begin{array}{c}\text { Positive margin } \\
\text { (\%) }\end{array}$ & $\begin{array}{l}\text { Blood loss } \\
\qquad(\mathrm{mL})\end{array}$ & $\begin{array}{l}\text { Length of stay } \\
\text { (days) }\end{array}$ & $\begin{array}{c}\text { Mortality } \\
(\%)\end{array}$ \\
\hline Montalti et al. (11)/2016 & 36 & 306 [53-790] & 13.9 & 11.1 & $415[0-1,500]$ & 6 [2-91] & 2.8 \\
\hline Melstrom et al. (6)/2018 & 29 & $191 \pm 75$ & 18 & 0 & $125 \pm 159$ & 3 [1-6] & 0 \\
\hline
\end{tabular}

operative procedure. Melstrom et al. suggested that robotically-assisted hepatectomy should be employed in cases where the location of tumors prohibits a classical laparoscopic approach (for example, in the case of superior/ posterior tumors), and in cases where the incision for an open operation dominates the course of recovery (6). Their policy of selecting incision-dominant cases for RLR is a very sympathetic concept when considering the advantages of MIS. Indeed, the benefit of RLR for minor resection of the posterosuperior segments has been demonstrated in several reports (7).

Generally, there is a learning curve for the MIS procedure. One of the major proposed advantages of RLR is the possibility of a shortened learning curve, especially in the context of parenchymal sparing resections. Although there are few published comparisons, it does appear that the learning curve for RLR is shorter than that associated with LLR (8).

Although the robotic approach seems more suitable for the minor parenchymal sparing resection of the posterosuperior segments, recent developments now mean that the laparoscopic approach can also be used safely in this context. In particular, several unique techniques have been developed in order to overcome the disadvantages of the laparoscopic approach (9). Compared with OLR, a metaanalysis study recently published by Zheng et al. showed that operations using LLR took longer, but were associated with lower complication rates and shorter hospital stays. No difference was observed in oncological outcomes between the two groups, and this finding was supported by a randomized controlled trial that obtained similar shortterm results (10). The postoperative hospital stay was shorter in the LLR group ( 2 vs. 4 days, $\mathrm{P}<0.001)$. Based on these results, it appears that LLR is safe and feasible, even for posterosuperior liver lesions, when it is performed in experienced centers (Table 1).

The number of studies comparing LLR and RLR is increasing. However, very few have described minor resection of lesions located posterosuperior segments. (Table 2) Montalti et al. performed a propensity scorematched analysis and compared the operative outcomes of LLR and RLR for posterosuperior lesions (11). Matched patients displayed no significant differences in blood loss, surgical time, hospital stay or R1 resection rate. On the other hand, the use of RLR was significantly associated with more intensive use of the Pringle maneuver and longer inflow occlusion times. Frequent use of the Pringle maneuver in RLR when compared to LLR was attributed to differences in the methods of liver transection. In LLR, liver transection was performed using a Cavitron Ultrasonic Surgical Aspirator (CUSA); such a device is not available in RLR, which is instead performed using the crush technique. This latter technique often requires intermittent Pringle maneuver, and the prolonged inflow occlusion time may affect the postoperative course. This may explain the trend of more severe complications in RLR group when compared to LLR, although this difference was not statistically significant. In addition, reduced instrumentation is one of the major limitations of RLR. 
Although RLR is still developing and is a relatively new procedure, several encouraging positive steps have been taken that may lead to its widespread adoption by the field. In the future, development of robotic technology and new robotic instruments will overcome the current weak points of RLR. We look forward to more studies designed to evaluate the role of RLR in transforming patients' lives.

\section{Acknowledgments}

Funding: None.

\section{Footnote}

Conflicts of Interest: All authors have completed the ICMJE uniform disclosure form (available at http://dx.doi. org/10.21037/hbsn.2019.11.02). The authors have no conflicts of interest to declare.

Etbical Statement: The authors are accountable for all aspects of the work in ensuring that questions related to the accuracy or integrity of any part of the work are appropriately investigated and resolved.

Open Access Statement: This is an Open Access article distributed in accordance with the Creative Commons Attribution-NonCommercial-NoDerivs 4.0 International License (CC BY-NC-ND 4.0), which permits the noncommercial replication and distribution of the article with the strict proviso that no changes or edits are made and the original work is properly cited (including links to both the formal publication through the relevant DOI and the license). See: https://creativecommons.org/licenses/by-nc-nd/4.0/.

\section{References}

1. Wakabayashi G, Cherqui D, Geller DA, et al.

Recommendations for laparoscopic liver resection: a report from the second international consensus conference held in Morioka. Ann Surg 2015;261:619-29.

2. Ciria R, Cherqui D, Geller DA, et al. Comparative Shortterm Benefits of Laparoscopic Liver Resection: 9000 Cases and Climbing. Ann Surg 2016;263:761-77.

3. Machairas N, Papaconstantinou D, Tsilimigras DI, et al. Comparison between robotic and open liver resection: a systematic review and meta-analysis of short-term outcomes. Updates Surg 2019;71:39-48.

4. Daskalaki D, Gonzalez-Heredia R, Brown M, et al. Financial Impact of the Robotic Approach in Liver
Surgery: A Comparative Study of Clinical Outcomes and Costs Between the Robotic and Open Technique in a Single Institution. J Laparoendosc Adv Surg Tech A 2017;27:375-82.

5. Guan R, Chen Y, Yang K, et al. Clinical efficacy of robotassisted versus laparoscopic liver resection: a meta analysis. Asian J Surg 2019;42:19-31.

6. Melstrom LG, Warner SG, Woo Y, et al. Selecting incision-dominant cases for robotic liver resection: towards outpatient hepatectomy with rapid recovery. Hepatobiliary Surg Nutr 2018;7:77-84.

7. Nota CL, Woo Y, Raoof M, et al. Robotic Versus Open Minor Liver Resections of the Posterosuperior Segments: A Multinational, Propensity Score-Matched Study. Ann Surg Oncol 2019;26:583-90.

8. Efanov M, Alikhanov R, Tsvirkun V, et al. Comparative analysis of learning curve in complex robot-assisted and laparoscopic liver resection. HPB (Oxford) 2017;19:818-24.

9. Kim S1, Han HS2, Sham JG, et al. Laparoscopic anatomical S7 segmentectomy by the intrahepatic glissonian approach. Surg Oncol 2019;28:158.

10. Aghayan DL, Fretland ÅA, Kazaryan AM, et al. Laparoscopic versus open liver resection in the posterosuperior segments: a sub-group analysis from the OSLO-COMET randomized controlled trial. HPB (Oxford) 2019;21:1485-90.

11. Montalti R, Scuderi V, Patriti A, et al. Robotic versus laparoscopic resections of posterosuperior segments of the liver: a propensity score-matched comparison. Surg Endosc 2016;30:1004-13.

12. Lee W, Han HS, Yoon YS, et al. Comparison of laparoscopic liver resection for hepatocellular carcinoma located in the posterosuperior segments or anterolateral segments: A casematched analysis. Surgery 2016;160:1219-26.

13. Scuderi V, Barkhatov L, Montalti R, et al. Outcome after laparoscopic and open resections of posterosuperior segments of the liver. Br J Surg 2017;104:751-9.

14. D'Hondt M, Tamby E, Boscart I, et al. Laparoscopic versus open parenchymal preserving liver resections in the posterosuperior segments: a case-matched study. Surg Endosc 2018;32:1478-85.

15. Okuno M, Goumard C, Mizuno T, et al. Operative and short-term oncologic outcomes of laparoscopic versus open liver resection for colorectal liver metastases located in the posterosuperior liver: a propensity score matching analysis. Surg Endosc 2018;32:1776-86.

Cite this article as: Ban D, Ishikawa Y, Tanabe M. Can robotic liver resection compensate for weaknesses of the laparoscopic approach? HepatoBiliary Surg Nutr 2020;9(3):385-387. doi: 10.21037/hbsn.2019.11.02 